\title{
Experience and Lessons of Tuberculosis Prevention and Control During COVID-19 Pandemic in Clinic
}

\author{
Jianqin Liang ${ }^{1 \#}$, Huiru An ${ }^{1 \#}$, Jin Zhou ${ }^{2 \#}$, Zhi Chen $^{1}$, and Wenping Gong ${ }^{1 *}$ \\ ${ }^{1}$ Army Tuberculosis Prevention and Control Key Laboratory/Beijing Key Laboratory of New Techniques of \\ Tuberculosis Diagnosis and Treatment, Institute for Tuberculosis Research, the 8th Medical Center, Chinese PLA \\ General Hospital, Beijing, China \\ ${ }^{2}$ Medical Department, the $8^{\text {th }}$ Medical Center, Chinese PLA General Hospital, Beijing, China \\ \#Jianqin Liang, Huiru An, and Jin Zhou contributed equally to this article.
}

\begin{abstract}
The coronavirus disease 2019 (COVID-19) and pulmonary tuberculosis (PTB) are respiratory infectious diseases spread by droplets. It is difficult to distinguish COVID-19 and PTB by their clinical symptoms and radiographic features. PTB prevention and treatment have become challenges during the COVID-19 pandemic. Here in, as long-term frontline health care workers (HCWs) in the TB department, we have summed up the following experience and lessons from a large number of clinical practices. We expect that these suggested strategies can help clinicians effectively reduce the risk of co-infection of COVID-19 and TB and reduce population morbidity and mortality.
\end{abstract}

\section{Keywords}

Tuberculosis, COVID-19, Infection Prevention and Control, Cross Infection, Health Care Workers (Hcws), Management

\section{Introduction}

The coronavirus disease 2019 (COVID-19) is caused by a novel coronavirus called severe acute respiratory syndrome coronavirus 2 (SARS-CoV-2). COVID-19 has spread rapidly, incredibly threatening people's lives and health worldwide [1]. Globally, as of 19 November 2020, there have been $55,928,327$ confirmed cases of COVID-19, including 1,344,003 deaths, reported to the World Health Organization (WHO, https://covid19.who.int/). COVID-19 is a novel respiratory infectious disease, and all age groups are susceptible to it. The disease spectrum ranges from mild symptoms of respiratory tract infection such as running nose, cough, and slight fever, to other complicated symptoms causing damage to intestines, liver, and nervous system, similar to people ill with TB $[2,3]$. Person-to-person transmission, community spreading, family cluster infection, and health care workers (HCWs)' infection make the condition more complicated. It was reported that $41.3 \%$ of the COVID-19 patients were infected in hospital in Wuhan, China [4]. According to China's law on preventing and controlling infectious diseases, COVID-19 has been included in class- $B$ infectious diseases and managed as class- $A$ infectious diseases (http://www.gov.cn/xinwen/2020-01/21/ content_5471158.htm).

TB is an airborne communicable disease and is identified as the second leading cause of death from infectious disease worldwide. The Global Tuberculosis Report 2020 indicated that more than 10 million people developed TB, and 1.4 million died from TB in 2019 [5]. Studies have shown that the COVID-19 epidemic has significantly impacted tuberculosis's incidence and mortality, making TB's prevention and control during the COVID-19 epidemic more challenging [5,6]. TB's clinical symptoms and radiographic features are not easily distinguished from COVID-19, especially in patients with typical manifestations. How to distinguish COVID-19 from pulmonary TB? What measures should HCWs take during the COVID-19 pandemic to ensure the standard treatment of outpatients and inpatients? Therefore, it is urgent to formulate effective prevention and treatment strategies to reduce the incidence and mortality of TB during the COVID-19 pandemic.

\footnotetext{
*Corresponding author: Wenping Gong, Army Tuberculosis Prevention and Control Key Laboratory/Beijing Key Laboratory of New Techniques of Tuberculosis Diagnosis and Treatment, Institute for Tuberculosis Research, the 8th Medical Center, Chinese PLA General Hospital, Beijing 100091, China, Tel: +86010-6677-5675

Accepted: June 21, 2021

Published online: June 23, 2021

Citation: Liang J, Huiru An, Zhou J, et al. (2021) Experience and Lessons of Tuberculosis Prevention and Control During COVID-19 Pandemic in Clinic. Ann Public Health Reports 5(1):201-206
} 
Our hospital's TB department has a history of more than 70 years in diagnosing and treating respiratory infectious diseases, especially TB. Moreover, during the fight against severe acute respiratory syndrome (SARS) 17 years ago, we created a history of zero infection among HCWs and accumulated rich experience in preventing and controlling sudden epidemics. Although experience on co-infection of TB and COVID-19 remains limited, it is anticipated that people ill with TB and COVID-19 may have poorer outcomes. TB patients' impaired immune function will increase the risk of co-infection with COVID-19, which will accelerate TB disease deterioration. This study aims to summarize some effective TB prevention and treatment strategies from our clinical experience to help HCWs improve TB diagnosis and treatment, reduce the co-infection of TB and COVID-19, and reduce incidence and mortality. At the same time, we also hope that these experiences and lessons can provide a reference for medical institution managers and clinic operators to deal with the challenges brought by these two diseases calmly.

\section{The Managements for TB Outpatient}

It is essential to raise the awareness of infection prevention, control, and disinfection of health workers and patients in TB outpatient to significantly reduce iatrogenic infections during the pandemic. Whether it is an HCW or a patient in the TB outpatient department, the following three suggestions should be followed, which will reduce the morbidity.

(1) In order to follow the epidemic prevention requirements of 'Prevent the spread of COVID-19 from both with and without of our country', which is the critical strategy in China to fight COVID-19, our hospital improved outpatient appointment system, and only retaining the emergency registration system.

(2) To reduce contact infection and avoid cross-infection, only one general clinic and an expert clinic are placed every day.

(3) If patients need to be admitted to the TB ward due to disease severity, they must be quarantined and observed outside the hospital for 15 days to exclude COVID-19before being admitted. HCWs working at registration offices and clinics should double-check inpatient procedures to ensure no cross-infection and imported cases in the hospital.

\section{HCWs management in the outpatient department}

$\mathrm{HCWs}$ in the outpatient department are the people who have the most contact with patients. They have the highest probability of being exposed to SARS-CoV-2. Therefore, formulating and strictly complying with the protection strategies for HCWs in the outpatient department is the key to reducing the cross-infection of COVID-19 in the hospital, and it is also the basis for the normal operation of the medical system. The following suggestions should be adopted and conducted by every $\mathrm{HCW}$ working in the outpatient department:

(1) Mastering COVID-19 related professional knowledge is a prerequisite for starting work. HCWs must pass the knowledge test of COVID-19 infection and prevention and the assessment of standardized putting on and taking off Personal Protective Equipment (PPE) before they can take up their jobs.

(2) Medical institutions must stock a sufficient amount of PPE, such as medical masks, N95 masks, medical gloves, goggles, protective clothing, disinfectants, etc. HCWs should wear these PPEs before coming into close contact with patients.

(3) The reception staff is responsible for monitoring the patients' temperature and instructing all patients and their families who enter the TB outpatient area to put on masks correctly.

(4) Patients with suspicious symptoms or who visited the area where COVID-19 was prevalent within 14 days should be guided to the fever clinics by staff according to the specified route for screening respiratory disease-related viruses and COVID-19. The suspected case should be immediately isolated and immediately report to the hospital's infection control commission. These measures will minimize the risk of other people being infected by COVID-19.

(5) For patients without suspicious symptoms, especially with a slight fever, a health worker should accompany them to the TB clinic, where the TB physician conducts related examinations. The physician should apply precautions for all patients, carefully inquire the patients' epidemiological history, be responsible for distinguishing COVID-19 from TB (Table 1).

(6) Outpatient physicians should strictly strengthen administrative controls. Doctors should recommend patients to receive health care at home, take medicine under guidance, and seek medical advice through online consultation if suffering cute complications.

(7) The policy of "Longtime prescription" should be clearly carried out. The prescription should be extended from 1 month to 3 months to reduce the number of TB patients to the hospital and ensure that the necessary treatment is provided. Meanwhile, TB patients should be recommended to get medicines on the internet platform with a prescription if there are no illness changes. If it deteriorates, the patient should go to the TB prevention and control center or community hospital to receive standard treatment.

\section{Patient management in the outpatient department}

During the epidemic, TB patients who came to the hospital for treatment were the primary source of COVID-19 infection imported from outside of the hospital. They are also highrisk groups for COVID-19 infection due to a possible negative impact of TB related immune dysregulation [7]. Patients who intend to go to the outpatient clinic must follow the following recommendations:

(1) All patients entering the TB clinic should put on a medical mask.

(2) All patients should be required to make an online appointment and queue up at the registration office with a distance of more than 1 meter. 
Table 1: Identification of tuberculosis and COVID-19.

\begin{tabular}{|l|l|l|}
\hline & COVID-19 & Pulmonary tuberculosis \\
\hline Pathogen & SARS-CoV-2 & Mycobacterium tuberculosis \\
\hline Transmission route & Respiratory droplets and contact transmission & Respiratory droplets transmission \\
\hline Susceptible population & $\begin{array}{l}\text { All age groups. older people and those with underlying diseases } \\
\text { more severe, children less affected }\end{array}$ & Quinquagenarian and low immune function \\
\hline Epidemiology history & The outbreak in the short term & Usually not an outbreak in the short term \\
\hline Symptom & $\begin{array}{l}\text { Acute onset, slight fever, dry cough, chest tightness, shortness } \\
\text { of breath }\end{array}$ & $\begin{array}{l}\text { Slow onset, slight fever, cough, night sweats, } \\
\text { malaise, }\end{array}$ \\
\hline Radiography & $\begin{array}{l}\text { In the early stage, multiple small patchy shadows and stromal } \\
\text { changes, mainly in the lung exudate, and then developing } \\
\text { multiple ground glass shadows and infiltrating shadows in } \\
\text { double lungs, and severe lung consolidation, with rare pleural } \\
\text { effusion and cavity }\end{array}$ & $\begin{array}{l}\text { Multisite, multiform, uneven density, voids, } \\
\text { lumpy shadows, or (and) with pleural } \\
\text { effusion }\end{array}$ \\
\hline Blood routine & $\begin{array}{l}\text { The white blood cell count: normal or decreased; } \\
\text { the lymphocyte count: normal or decreased }\end{array}$ & $\begin{array}{l}\text { The white blood cell count: with normal } \\
\text { limits; the lymphocyte count: increased }\end{array}$ \\
\hline Diagnosis & $\begin{array}{l}\text { Nasopharyngeal swab or sputum positive for the nucleic acid } \\
\text { of SARS-CoV-2, or virus gene sequencing highly homologous to } \\
\text { known SARS-CoV-2, or positive for antibody specific lgM and } \\
\text { IgG of SARS-CoV-2 }\end{array}$ & $\begin{array}{l}\text { Positive sputum smears for acid-fast } \\
\text { staining or (and) culture for mycobacterium } \\
\text { tuberculosis of sputum }\end{array}$ \\
\hline Therapy & $\begin{array}{l}\text { No effective drugs } \\
\text { E }\end{array}$ & Effective anti-TB drugs \\
\hline
\end{tabular}

Table 2: Screening form for COVID-19.

\begin{tabular}{|c|c|c|c|c|c|c|}
\hline \multirow{2}{*}{ Patient's name } & \multirow{2}{*}{\multicolumn{2}{|c|}{ Gender }} & Male & \multirow{2}{*}{ Age } & \multirow{2}{*}{ - ID number } & \\
\hline & & & Female & & & \\
\hline \multicolumn{7}{|l|}{ Screening programs } \\
\hline \multicolumn{3}{|c|}{$\begin{array}{l}\text { Temperature } \\
\text { If hospitalization is required, the nurse measures again }\end{array}$} & ${ }^{\circ} \mathrm{C}$ & The nurse signature & & \\
\hline \multirow{3}{*}{ Clinical feature } & \multicolumn{4}{|c|}{$\begin{array}{l}\text { Fever? (If the fever is } \geq 37.3^{\circ} \mathrm{C} \text {, the following screening should be conducted by } \\
\text { the fever clinic) }\end{array}$} & YES $\square$ & NO $\square$ \\
\hline & \multicolumn{4}{|c|}{ Does CT show the imaging features of pneumonia? } & YES $\square$ & $\mathrm{NO} \square$ \\
\hline & \multicolumn{4}{|c|}{$\begin{array}{l}\text { The total number of white blood cells was normal or decreased, or the } \\
\text { lymphocyte count was decreased? }\end{array}$} & YES $\square$ & NO $\square$ \\
\hline \multirow{4}{*}{$\begin{array}{l}\text { Epidemiological } \\
\text { history }\end{array}$} & \multicolumn{4}{|c|}{$\begin{array}{l}\text { Travel history or residence history in the Wuhan area or other areas with } \\
\text { continuous transmission of local cases within } 14 \text { days before onset? }\end{array}$} & YES $\square$ & NO $\square$ \\
\hline & \multicolumn{4}{|c|}{$\begin{array}{l}\text { Have you been exposed to fever or respiratory symptoms from Wuhan or } \\
\text { other areas where local cases continue to circulate within } 14 \text { days before } \\
\text { onset? }\end{array}$} & YES $\square$ & NO $\square$ \\
\hline & \multicolumn{4}{|c|}{$\begin{array}{l}\text { A cluster of disease? (many people around the same fever and other } \\
\text { symptoms) }\end{array}$} & YES $\square$ & NO $\square$ \\
\hline & \multicolumn{4}{|c|}{$\begin{array}{l}\text { Epidemiological association with confirmed cases? (surrounding or in close } \\
\text { contact with confirmed cases) }\end{array}$} & YES $\square$ & NO $\square$ \\
\hline \multirow{3}{*}{ Patient commitment } & \multicolumn{6}{|c|}{ The epidemiological history is real. If not, I will bear all the responsibility for the consequences } \\
\hline & \multicolumn{6}{|c|}{ Patient or family member Signature: } \\
\hline & & & & Time & \multicolumn{2}{|c|}{ Month Day, 2020} \\
\hline \multirow{3}{*}{ Conclusion } & \multicolumn{3}{|c|}{$\begin{array}{l}\text { The patient with this fever does not have the } \\
\text { diagnostic conditions for the suspected case of } \\
\text { pneumonia caused by SARS-CoV-2 infection }\end{array}$} & \multicolumn{3}{|c|}{ The patient is admitted to hospital } \\
\hline & $\begin{array}{l}\text { Fever outpatient physician } \\
\text { signature: }\end{array}$ & \multicolumn{2}{|c|}{ (signature and seal) } & Physician signature: & \multicolumn{2}{|c|}{ (signature and seal) } \\
\hline & Month & Day, & 2020 & Time: & Month Day, 2 & \\
\hline
\end{tabular}

(3) After entering the reception room in the order of registration, patients should receive an epidemiological investigation and fill in a questionnaire honestly (Table 2).

(4) Patients with fever symptoms must inform HCWs in advance and seek medical treatment under the guidance of HCWs to avoid contact with other patients.
(5) The patients' examination should be conducted according to specific routes under the guidance of HCWs.

\section{The managements for TB inpatient}

Compared with outpatients, inpatients can receive more comprehensive and systematic treatment, which is crucial for those with more severe illnesses. However, due to the 
influence of Mycobacterium tuberculosis on their immunity, hospitalized patients are less able to resist COVID-19 infection. Therefore, to reduce TB inpatients' mortality, both HCWs and patients must follow the following recommendations.

\section{HCWs management in TB wards}

(1) The HCWs of the TB ward should be taken temperature before and after work every day, and only the temperature is normal can they be allowed to enter the wards.

(2) The HCWs should strictly follow the standard quarantine measures for individuals in the context of COVID19in the hospital and the standard of hand hygiene before and after closely contacting with patients.

(3)The HCWs should wear a non-woven medical cap and medical mask correctly. The second level protection principle should be strictly followed when entering wards. When patients develop respiratory dysfunction or multiple organ dysfunction syndromes, they should be transferred to the TB intensive care unit. The third level protection principle should be followed when endotracheal intubation or bronchoscope underwent [1].

\section{Patient management in TB wards}

(1) It is valuable to establish a well-equipped triage station at the ward's entrance, supported by trained HCWs. Patients should wear masks and follow the designated route to enter the TB ward to receive treatment in isolation and not go out of the ward with permission. The examination outside the ward should be carried out at the appointed time in a particular order under guidance.

(2) A HCW in the elevator of TB wards should guide patients, take temperature, and instruct patients to wear masks correctly. After these, patients should be guided to the ward for hospital administration. Patients should receive treatment in a separate room for the first three days and should not go out without permission.

(3) Ward visiting should be strictly limited. Ordinary patients should not be allowed to be visited. A time-limited and number-limited visiting system should be carried out on patients in severe conditions.

(4) Patients should pay more attention to personal hygiene, proper diet, enough rest, appropriate exercise, and press the red alert button on the wall to turn to the HCWs for help at any time when feeling anything wrong.

\section{Environment management in TB department}

Our experience shows that patients like to gather in airconditioned hospital areas in summer and warm indoors in winter. Confined spaces and crowds provide conditions for the spread of COVID-19 and TB [8]. It is particularly important to pay more attention to environmental management during the COVID-19 pandemic.

(1) The corridors, lobbies, clinics, and wards should be disinfected, and proper ventilation measures should be taken every day.
(2) The floor and the surface of medical equipment should be cleaned with a chlorine-containing disinfectant or $75 \%$ alcohol twice a day. Droplets contained viruses are too heavy to hang in the air, so they quickly fall on floors or surfaces. The surface that doctors and patients frequently contact, such as electrocardiograph monitor, blood pressure monitor, stethoscope, bed rail, door handle, should be disinfected as well.

(3) Disinfected the air by irradiation of ultraviolet light for at least one hour, twice a day.

(4) Disposable medical supplies, patient body fluids, and contaminated dressings should be placed in medical plastic bags (yellow plastic bags in China) with a warning label. The medical waste collectors should be closely sealed, and the process of handover should be standardized.

(5) The patients' specimens should be kept in a fixed, specially marked container. It would be best that the containers were disposable, but the fact is that the containers are usually recyclable in China. Therefore, the containers should be disinfected by soaking in chlorine-containing disinfectant of $2000 \sim 5000 \mathrm{mg} / \mathrm{L}$ or $75 \%$ alcohol after using.

(6) The patients' bedclothes should be changed at least twice a week or at any time when contaminated.

(7) All waste generated by patients should be treated as medical waste, collected, and managed by trained HCWs.

(8) The infection control commission should delegate trained HCWs to conduct regular sampling and testing of indoor air, equipment surfaces, and HCWs' fingers.

\section{Hospitalization procedures for TB patients}

A professional doctor should inquire the patients about their symptoms and epidemic history. The patients highly suspected of TB depend on typical TB symptoms, images, and related laboratory evidence should be admitted to the hospital. In that case, the outpatient nurses will send the patients to an isolation ward according to the designated route. At the elevator entrance of the ward, a well-trained HCW should be arranged to monitor each person's body temperature and assist in filling out the COVID-19 epidemic questionnaire and personal tracking information. After 72 hours of observation and evaluation, the TB patient will be transferred to the ordinary multi-person ward for further treatment. If COVID-19 is still suspected, the patient will be transferred to the fever outpatient for further investigation. The nucleic acid test and antibody screening will be carried out. After the diagnosis, the patient will be sent to the designated hospital of COVID-19 (Figure 1).

\section{Conclusions}

In summary, during the COVID-19 pandemic, the TB departments face a challenging task and need to be actively engaged in ensuring an effective and rapid response to COVID-19. The principles of controlling the infection source, cutting off the transmission route, and protecting susceptible populations must be strictly followed and implemented. No matter in TB clinics or wards, HCWs should increase their level 


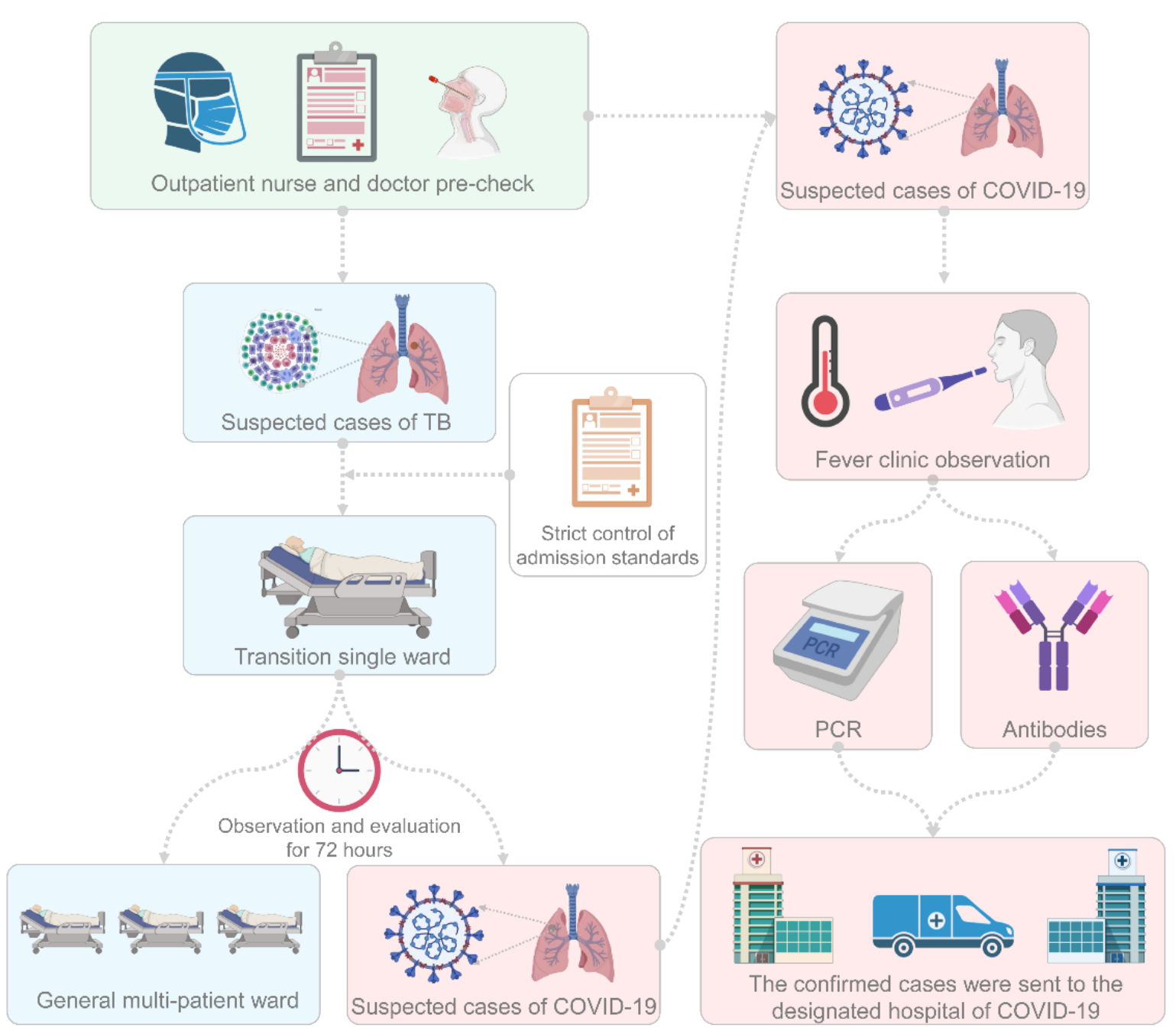

Figure 1: The standard hospitalization procedures for tuberculosis department.

of preparedness, alert, and response to identify. TB patients should pay more attention to personal protection and follow the rules and guidelines given in this study. For people with typical suspicious symptoms of TB such as fever, night sweats, and cough, online counseling is strongly recommended, and digital health technologies should be intensified instead of visiting TB centers. Those diagnosed with TB need timely and systematic treatment. Patients are recommended to live in an isolation room when admitted to the TB ward according to the disease's severity. During the COVID-19 pandemic, it is vital to ensure that essential treatment for handling longstanding health problems to protect people's lives with TB.

\section{Data Availability}

All data generated or analyzed during this study are included in this published article and its supplementary information files.

\section{Highlights}

1. HCWs and patients of the TB clinics and wards need to be trained, respectively.

2. The patients with severe TB and complications should be admitted in time.
3. Standardize environmental infection control measures and diagnosis and treatment procedures for outpatients and inpatients to achieve "zero cross-infection" of TB and COVID-19 among HCWs.

\section{Acknowledgments}

We thank all the staff working in TB departments of our hospital for their professional guidance and information during this study.

\section{Author contributions}

Conceptualization: Jianqin Liang, Wenping Gong; Methodology: Huiru An, Zhi Chen, Jin Zhou, and Wenping Gong; Writing original manuscript: Jianqin Liang; Review and revising manuscript: Jianqin Liang and Wenping Gong, All authors reviewed and approved the final manuscript.

\section{Funding}

This research did not receive any specific grant from funding agencies in the public, commercial, or not-for-profit sectors.

\section{Competing interests}

The authors declare no conflict of interest. 


\section{Compliance with Ethics Guidelines}

This manuscript is a commentary and does not involve a research protocol requiring approval by the relevant institutional review board or ethics committee.

\section{References}

1. Phelan AL, Katz R, Gostin LO (2020) The novel coronavirus originating in Wuhan, China: Challenges for global health governance. Jama 323: 709-710.

2. (2020) Treatment protocols for COVID-19. In: NHNC. (7th edn), Beijing, China,1-22.

3. Shrinivasan R, Rane S, Pai M (2020) India's syndemic of tuberculosis and COVID-19. BMJ global health. 5: e003979.
4. Wang D, Hu B, Hu C, et al. (2020) Clinical characteristics of 138 hospitalized patients with 2019 novel coronavirus-infected pneumonia in Wuhan, China. Jama 323: 1061-1069.

5. WHO (2020) Global tuberculosis report 2020.

6. Glaziou P (2020) Predicted impact of the COVID-19 pandemic on global tuberculosis deaths in 2020. MedRxiv.

7. Torre A, Aliberti S, Castellotti PF, et al. (2020) Preliminary observations on IGRA testing for TB infection in patients with severe COVID-19 eligible for immunosuppressive therapy. Respiratory medicine 175: 106204.

8. Rogers JH, Link AC, McCulloch D, et al. (2021) Characteristics of COVID-19 in Homeless Shelters: A community-based surveillance study. Ann Intern Med 174: 42-49.

DOI: $10.36959 / 856 / 519$

Copyright: (C) 2021 Liang J, et al. This is an open-access article distributed under the terms of the Creative Commons Attribution License, which permits unrestricted use, distribution, and reproduction in any medium, provided the original author and source are credited. 